\title{
Design and Specification Compilation of a Modularized Prefabricated High-rise Steel Frame Structure with Inclined Braces Part I: Integral Structural Design
}

\author{
Ailin $\mathrm{ZHANG}^{1}$, Xuechun $\mathrm{LIU}^{1 *}$, Chen TIAN ${ }^{1}$, Xun ZHANG ${ }^{1}$, Yongqiang TAN $^{2}$ \\ ${ }^{1}$ Beijing Engineering Research Center of High-rise and Large-span Prestressed Steel \\ Structures, Beijing University of Technology, Beijing 100022, China \\ ${ }^{2}$ Broad Sustainable Building Technology Ltd, Yueyang 414600, China \\ *Corresponding author's e-mail: liuxuechun@bjut.edu.cn
}

\begin{abstract}
Modularized prefabricated steel structures have certain obvious advantages, i.e., rapid construction, industrial-scale production and pro-environmental aspects, and are the main method in industrialization of steel structures. Although applications of these structures have been reported all over the world, in most cases, the steel structural systems are only suitable for low-rise buildings, and their application in high-rise buildings is quite limited. This paper proposes a new type of modularized prefabricated high-rise steel frame structure with inclined braces. Based on the T30 hotel building, the mechanical properties, failure mode, failure mechanism and elastic-plastic development laws are investigated by using the elastic design of a structure under various load conditions, the analysis of the internal force and displacement responses under frequent earthquakes via the response spectrum method and linear time-history analysis, the static elastic-plastic pushover analysis under rare earthquake conditions. According to finite element simulations and testing, elastic and elastic-plastic structural design methods are proposed in this paper. This work provides an important reference for research and design of the same type of modularized prefabricated high-rise steel structures, and the design method has been compiled into design specification.
\end{abstract}

\section{KEYWORDS}

Modularized prefabrication; high-rise steel structure; structural design formula; elastic design; pushover analysis

\section{INTRODUCTION}

As shown in Figure 1, The T30 hotel building is located in Xiangyin county, Yueyang city, Hunan province of China, and is a 30-story building. The safety degree of the structural design is level 2, the design reference is 50 years, the seismic fortification intensity is $7^{\text {th }}$ 
degrees. As the structure of the T30 building represents a new type of structural system, the seismic fortification intensity is increased to $8^{\text {th }}$ degrees. All components of the structure are produced in factory and transported to the construction site for rapid assembly using high strength bolts. Compared with traditional reinforced concrete structures, the prefabricated steel structures offer obvious advantages, i.e., lighter weight, short construction period, low labor intensity, and high industrialization level, and it is environmentally friendly (Zhang 2013). Currently, prefabricated structure is widely used in Europe, the United States, Japan, Australia and other developed countries as an important form of building structure (Lara 2009; Gong 2001; Dao 2013; Wang 2012;). However, most of them are low-rise structures, and applications for high-rise structures are rare.

This project adopts a new type of modularized prefabricated steel frame structure with inclined braces for high-rise buildings. The columns are square steel tubes, the beams are truss beams, the inclined braces are arranged near the beam-column joints, the level of industrialization exceeding $90 \%$. Only two months are required to complete the installation of the main structure and the walls, with a construction period shortened by $90 \%$. This paper primarily introduces the methods of structural design. Using finite element simulation of the overall structure, the response spectrum method and linear time-history analysis, the internal force and displacement responses under frequent earthquakes were obtained and compared with the current standards. By synthesizing the research results and experiences, a design method for this structure was proposed.

\section{SYSTEM COMPOSITION}

A modularized prefabricated steel frame structure with inclined braces is primarily composed of two modules: the main floor and columns with inclined braces. The components within the module are welded in factory, and high-strength bolts are used to connect the different modules at site. As shown in Figure 2, the main floor consists of column bases, a truss beam and profiled steel sheet-concrete composite slabs. The truss beam is welded with $\mathrm{C}$-shaped steel, angle steel and steel plates. The lattice form facilitates the pre-laying performance of the equipment. The design of the column base not only connects the transverse and longitudinal truss beams and slabs together as a motherboard module but also easily connects the main floor and the upper and lower inclined-brace columns.
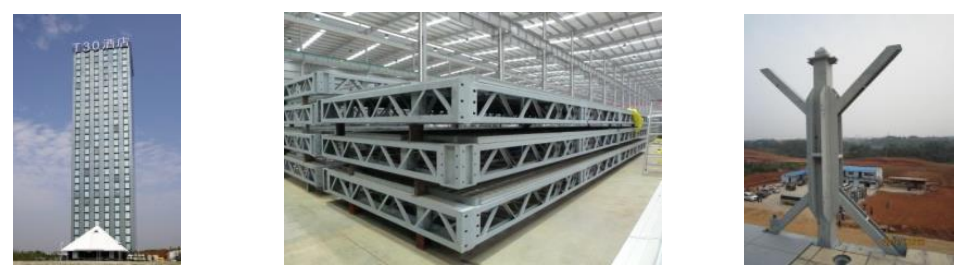

Figure 1. T30 hotel building. Figure 2. Main floor. Figure 3. Inclined-brace column.

As shown in Figure 3, the column with inclined braces consists of a column and the inclined braces. One end of the inclined braces is connected to the column, and the other end is connected to the truss beam. The column uses square steel tubes, and the braces are arranged at the sides of the column. According to the layout, single-sided brace columns, double-sided brace columns, three-sided brace columns and four-sided brace columns are possible. An ordinary steel column has no braces on any side. The main floor and the column with inclined braces are connected through the flange at the end of the square steel tube 
column and column base using high strength bolts. Figure 4 shows an assembly sketch of the structure.

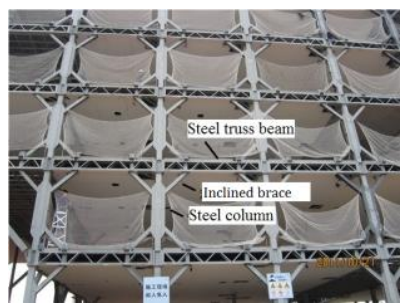

(a) Structural image

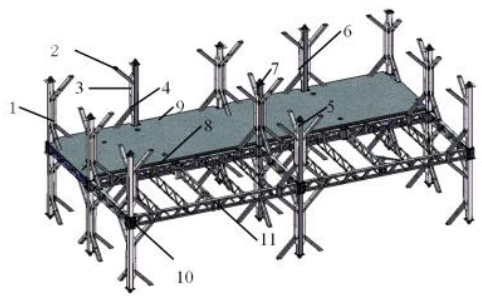

(b) Structural sketch

1-Column; 2-Inclined brace; 3-Column stiffening ribs; 4-Single-sided braced column; 5-Three-sided braced column; 6-Double-sided braced column; 7-Four-sided braced column; 8-Hanging box; 9-Main floor; 10-Column base; 11-Truss beam

Figure 4. Modularized prefabricated steel frame structure with inclined braces.

As shown in figure 5, using this technology, in China, the T30 hotel, S30 apartments (30-story high-rise), and a series of other multi-rise buildings have been built in Hunan province, a 26-story office building was built in Shanxi province, a 25-story technology mansion was built in Ningxia province, and an 11-story office building was built in Shandong province. This paper uses the T30 hotel building as a case study for design methods that could be applied to other similar structural systems in general and provide a basis from which to compile design standards for this type of structural system in particular.
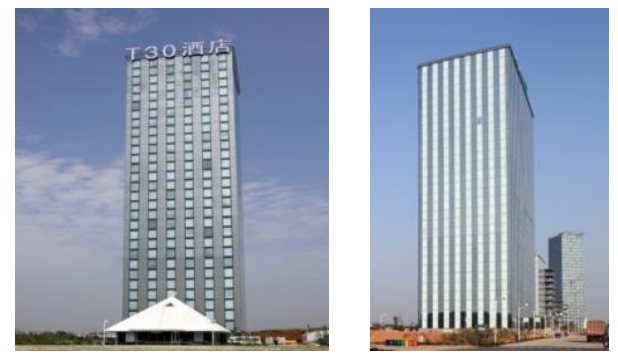

(a) T30 high-rise hotel

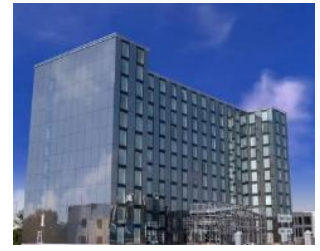

(d) 11-story office building (b) S30 high-rise apartment

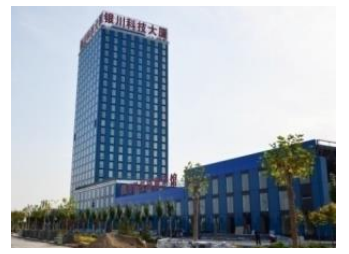

(e) 25-story technology mansion

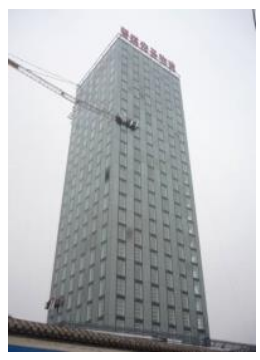

(c) 26-story office building

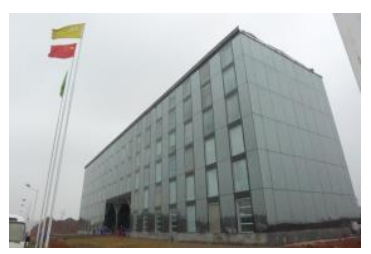

(d) 6-story office building

Figure 5. Built-up projects.

\section{COMPUTATIONAL MODELING}

The currently popular software Etabs, Sap2000, ANSYS and Midas were chosen for the finite element analysis and were used to perform the structural analysis and design in this paper, including static analysis, response spectrum analysis and elastic time-history analysis. The computational model shown in Figure 6 and 7, with the section size and type of each component shown in Table 1. The steel materials are all Q345B type. 


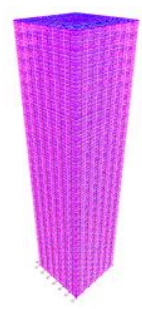

(a) Axonometric view

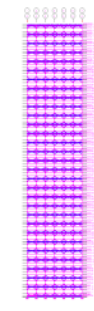

(b) Elevation view

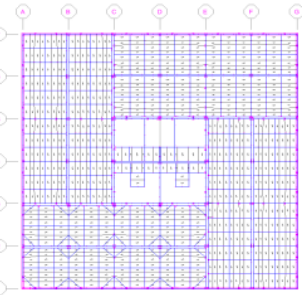

(c) Plan view

Figure 6. Finite element model of the entire structure in ETABS.

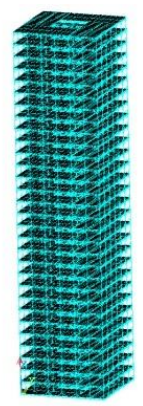

(a) Overall model

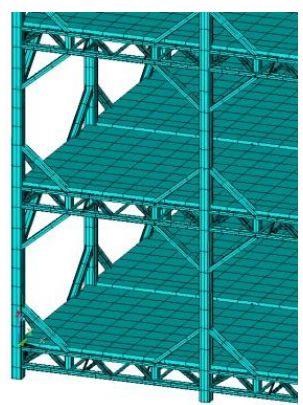

(b) Local member of one floor

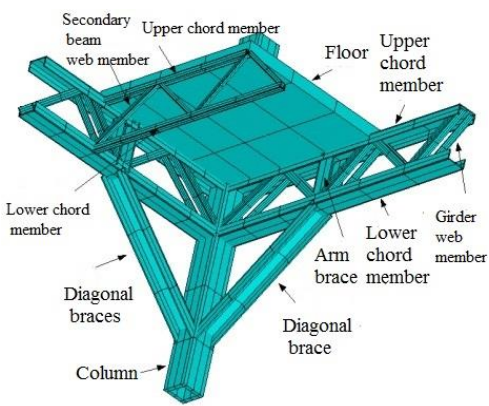

(c) Structure detail

Figure 7. Finite element model in ANSYS.

Table 1. Member section size and type.

\begin{tabular}{|c|c|c|}
\hline No. of & Location & Member \\
\hline \multirow[b]{2}{*}{ Segment } & Truss chord & $\mathrm{C} 160 \times 80 \times 8$ \\
\hline & Secondary beam chord & $\mathrm{C} 80 \times 80 \times 6$ \\
\hline 3 & Truss web & $2 \mathrm{~L} 56 \times 8$ \\
\hline$\left(1^{\text {th }}-10^{\text {th }}\right.$ & Secondary beam web & $\mathrm{L} 50 \times 4$ \\
\hline \multirow[t]{2}{*}{ story) } & Column & B $200 \times 200 \times 32$ \\
\hline & Inclined braces & $\mathrm{C} 160 \times 90 \times 10$ \\
\hline \multirow{4}{*}{$\begin{array}{l}\text { Segment } \\
2 \\
\left(11^{\text {th }}-21^{\text {th }}\right.\end{array}$} & Truss chord & $\mathrm{C} 160 \times 80 \times 8$ \\
\hline & Secondary beam chord & $\mathrm{C} 80 \times 80 \times 6$ \\
\hline & Truss web & $2 \mathrm{~L} 50 \times 6$ \\
\hline & Secondary beam web & $\mathrm{L} 50 \times 4$ \\
\hline \multirow[t]{2}{*}{ story) } & Column & B $200 \times 200 \times 22$ \\
\hline & Inclined braces & $\mathrm{C} 140 \times 90 \times 8$ \\
\hline \multirow{4}{*}{$\begin{array}{c}\text { Segment } \\
1 \\
\left(21^{\text {th }}-30^{\text {th }}\right.\end{array}$} & Truss chord & $\mathrm{C} 160 \times 80 \times 6$ \\
\hline & Secondary beam chord & $\mathrm{C} 80 \times 80 \times 6$ \\
\hline & Truss web & $2 \mathrm{~L} 50 \times 6$ \\
\hline & Secondary beam web & $\mathrm{L} 50 \times 4$ \\
\hline \multirow[t]{2}{*}{ story) } & Column & B $200 \times 200 \times 12$ \\
\hline & Inclined braces & $\mathrm{C} 140 \times 90 \times 8$ \\
\hline
\end{tabular}

\section{LOAD CASES AND SEISMIC WAVE SELECTION}

The response spectrum method and linear time-history analysis were adopted to calculate the structural responses, which considers horizontal bi-directional earthquakes, and the linear time-history analysis adopts the Newmark direct integral method. The structural damping ratio is 0.03 under frequent earthquakes, and 0.05 under rare earthquakes. The 1979 
ELCENTRO waves, TAFT waves and a set of artificial waves are selected for elastic and elastic-plastic time-history analysis. Seismic waves in the $\mathrm{X}, \mathrm{Y}$, and $\mathrm{Z}$ directions are input at the same time. The peak acceleration is $70 \mathrm{~cm} / \mathrm{s}^{2}$ under frequent earthquakes and $400 \mathrm{~cm} / \mathrm{s}^{2}$ under rare earthquakes. The ratios of peak acceleration along the $\mathrm{X}, \mathrm{Y}$ and $\mathrm{Z}$ directions are 1:0.85:0.65. The maximum envelope combination of the internal force obtained by the response spectrum method and linear time-history analysis is adopted for the design load combination. For the first two period, the response spectra transferred from the time history are similar to the response spectrum of the code and are consistent with the selection criteria of seismic waves. In other words, this result means that the average seismic response coefficient curve of several time-history curves and the seismic response coefficient curve of the mode-superposition response spectrum method appear to match in terms of statistical significance (Qu 2011).

\section{ANALYSIS RESULTS}

\section{Modal analysis}

The Wilson Ritz vector method is applied during the process of modal analysis to effectively find the natural vibration mode with high mass participation coefficients. The sum of the modal mass participation coefficients is greater than $90 \%$, which meets the code requirements. The first- and second-order modes are horizontal vibrations, The third-order mode is torsional vibration. The ratio of the torsional vibration period and horizontal vibration period meets the code requirements.

Table 3. Natural vibration period of structure.

\begin{tabular}{ccccccc}
\hline Modal & 1 & 2 & 3 & 4 & 5 & 6 \\
\hline Period (Etabs) s & 3.29 & 3.22 & 2.45 & 1.12 & 1.1 & 0.8 \\
Period (ANSYS) s & 3.11 & 3.04 & 2.13 & 1.06 & 1.04 & 0.77 \\
Difference \% & 5.79 & 5.92 & 15.02 & 5.66 & 5.77 & 3.90 \\
\hline
\end{tabular}

\section{Story displacement and drift angle}

The maximum elastic story drift angle are far less than the limit requirements of $1 / 250$ in the Code for seismic design of buildings (GB50011-2010) and Technical specification for steel structure of tall buildings (JGJ 99-98). The largest story drift angle occurs at the 11th story. The drift angle displays sharp changes at the $11^{\text {th }}$ and $21^{\text {th }}$ stories. Because the cross-sections of the columns at these two stories shift to smaller sizes, the vertical stiffness changes as well. It can be observed from the story drift angle under frequent earthquakes and wind loads that as the lateral structural stiffness becomes larger, the maximum displacement falls below the code limits. However, in this case, the internal forces of certain members reach the design strength, indicating poor deformation ability of the structure. Because this structural system is new, the story drift angle must be controlled more strictly compared with the traditional steel structure. 

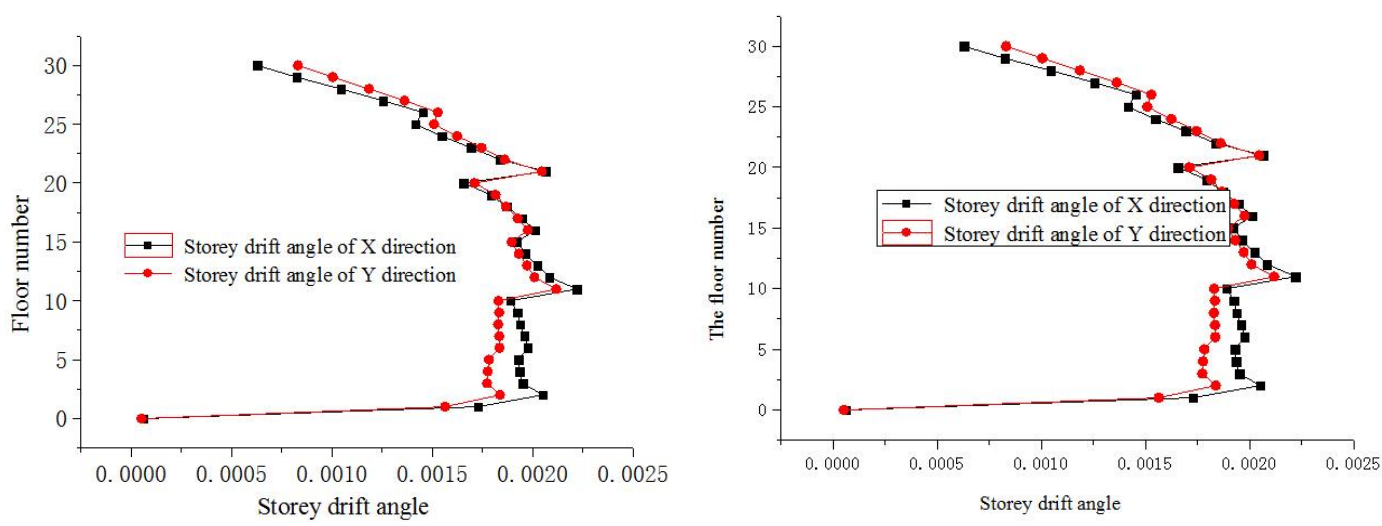

Figure 8. Story drift angle under earthquakes. Figure 9. Story drift angle under wind

\section{Component design}

The C-shaped steel truss upper chord is a compression- flexure member. Because the concrete slabs and truss upper chords are connected by studs arranged evenly along the upper chord with a fixed distance, the lateral instability and in-plane instability of the upper chord can be restricted. Therefore, only the strength calculation is needed, and the stability calculation can be ignored. If no concrete slab connects the upper chord, the in-plane effective length of the upper chord is the length between the joints connected with web members, and the out-of-plane effective length of the upper chord is the distance between lateral brace points. According to formulas (1), the strength of points 1 to 4 can be calculated as shown in Figure 10. According to formulas (2)-(3), the stability of the components that revolve around the Xand Y-axis also could be calculated.

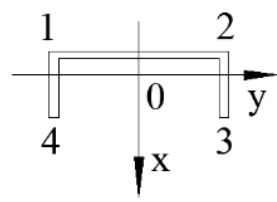

(a) upper chord

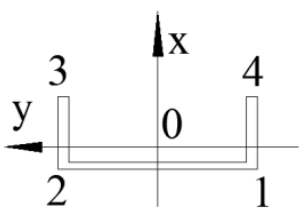

(b) lower chord

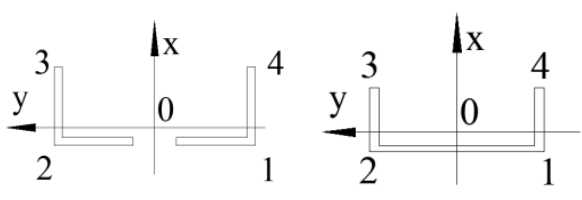

(c) web member

(d) Inclined brace.

Figure 10. Member section

$\frac{N}{A_{n}} \pm \frac{M_{x}}{\gamma_{1 x} W_{\mathrm{lnx}}} \pm \frac{M_{y}}{\gamma_{1 y} W_{\mathrm{lny}}} \leq f / \gamma_{\mathrm{RE}}$

$\frac{N}{\varphi_{\mathrm{x}} A} \pm \frac{\beta_{\mathrm{mx}} \cdot M_{x}}{\gamma_{1 x} W_{\mathrm{lx}}\left(1-0.8 \frac{N}{N_{\mathrm{Ex}}^{\prime}}\right)} \pm \eta \frac{\beta_{\mathrm{ty}} \cdot M_{y}}{W_{1 y}} \leq f / \gamma_{\mathrm{RE}}$

Where the parameters are taken according to the Code for design of steel structures (GB50017-2003).

The C-shape steel truss lower chord is a compression- flexure member. The in-plane effective length of the lower chord is the length between the joints connected with a web member, and the out-of-plane effective length of the lower chord is the distance between the lateral brace points. The main keel of the permanent furred ceiling, which is welded reliably to the lower chord, could be treated as a lateral brace. The two L-shape steel web members could be simplified as an individual component of the double L-shaped steel. The in-plane and out-of-plane effective length of the web member is 0.8 times the length between the joints connected with the chord. The $\mathrm{C}$-shape steel inclined brace is a compression-flexure member. 
The in-plane and out-of-plane effective length of the web member is the length between the joints. Using the second-order elastic or elastic-plastic analysis, which considers the p- $\Delta$ effect and large deformation, the internal force of the columns can be obtained and used in the strength and stability design for column with inclined braces. The effective length of the middle segment of column is 1.2, and each segment at the end of column is 1.0 (LIU Xuechun 2015a). According to the formula stated above, the design of the internal force for each component is tested. The analysis shows that most of the upper and lower chords and inclined braces display a relatively low equivalent stress ratio, whereas the truss chords and web members that connected the braces usually have a high stress ratio. Due to the layout of the inclined braces, the stress ratio of the web members enclosed by the brace is reduced significantly. This conclusion is further verified by the stress distribution and failure mode obtained from the frame experiment (LIU Xuechun 2015b).

\section{PUSHOVER ANALYSIS}

Pushover analysis is performed using the finite element model in ANSYS. Due to the simple and inerratic structure type, the first two vibration modes are primarily considered. Inverted triangular distributed total earthquake reactions are applied to the structure model. The largest ultimate story drift angle is $1 / 119$ in $\mathrm{X}$ direction and 1/105 in X direction, which are far less than the limit of 1/50 in the code (GB50011-2010). It can be observed that the lateral stiffness of this structure system is high, and the ultimate story drift angel meets the code requirements upon first consideration. However, such a structure displays poor ductility performance.

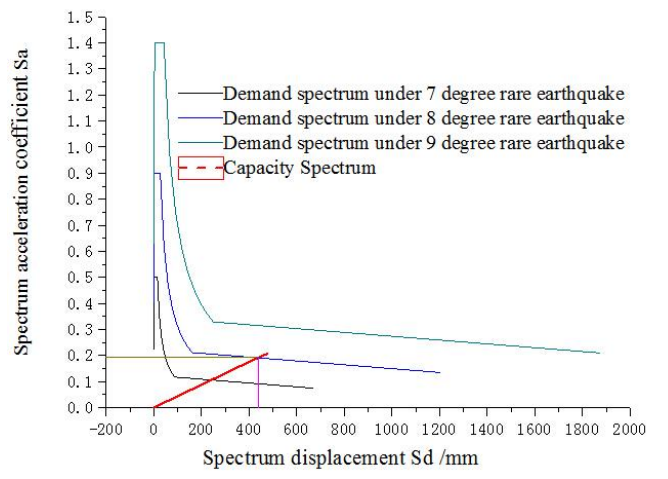

(a) X-direction

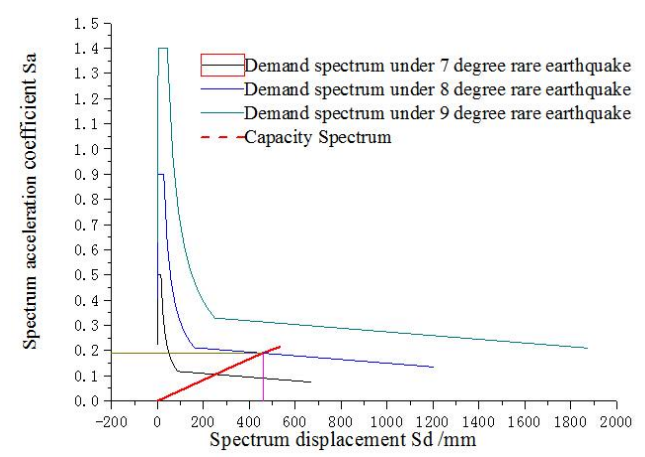

(b) Y-direction

Figure 11. Capacity spectrum and demand spectrum.

Using the capacity spectrum and the demand spectrum along the X-direction in Figure 11(a), the performance point in the $\mathrm{X}$-direction under an $8^{\text {th }}$ degree rare earthquake can be found. The corresponding vertex displacement is $620 \mathrm{~mm}$, and the total base reaction is $11970 \mathrm{kN}$. The failure rate of the Q345 steel components is $0.58 \%$, and the failure rate of the concrete floors is $1.02 \%$ at the performance point. Based on the available data, we draw the conclusion that the structural failure rate is quite low, and the overall performance of the structure is elastic. The damage locations are primarily distributed in a few web and chord members of the main truss.

\section{CONCLUSIONS}

(1) The relationship between the story displacement and the height of the floor is linear. The seismic performance meets the current code requirements and has a large lateral stiffness. 
As a newly developed system, the story drift angle should be controlled more strictly.

(2) The main function of the inclined braces is to decrease the effective length of the column and to expand and strengthen the joint region simultaneously.

(3) In the yield mechanism of this structural system, the web member of the beam fails first, followed by the chord member, and the column stress is less than the yield strength. The yield mechanism of the structure is reasonable, and the structure exists primarily in the elastic state under rare earthquakes without collapse.

(4) This paper introduces a design method for the modularized prefabricated high-rise steel frame structure with inclined braces, which is compiled into the relevant specifications and provides an important reference for design and development in the future.

\section{ACKNOWLEDGMENTS}

This work was supported by the National Science Foundation of China (51278010). The model tests of the beam-column joint and frame were conducted at and financially supported by Broad Sustainable Building Technology Ltd.

\section{REFERENCES}

Applied Technology Council(1996). Seismic evaluation and retrofit of concrete buildings.ATC-40 Report, Vol.1 and Vol. 2. California, USA: ATC,1996.

Applied Technology Council(1996). Seismic evaluation and retrofit of concrete buildings.ATC-40 Report, Vol.1 and Vol. 2. California, USA: ATC,1996.

Dao, T. and van de Lindt, J(2013). Seismic performance of an innovative light-frame cold-formed steel frame for midrise construction. J. Struct. Eng. SPECIAL ISSUE: Cold-Formed Steel Structures, 2013,139(5):837-848.

Gong Xiao-yun, Yan Hong(2001). Discussion on application of prefabricated houses in foreign countries. Industrial Construction 2001(08):17-19.

GB50017-2003(2003). Code for design of steel structures. China Planning Press 2003.

GB50011-2010(2010). Code for seismic design of buildings. China Planning Press 2010.

JGJ 99-98(2013). Technical specification for steel structure of tall building. China Architecture \& Building Press 2013.

Lara Jaillon, C. S Poon(2009). The evolution of prefabricated residential building systems in Hong Kong: A review of the public and the private sector. Automation in Construction 2009,18(3): 239-248.

Liu Xuechun, Xu Axin, Zhang Ailin(2015). Research on the Integral Stability Behaviors of Modularized Prefabricated Steel Structures with Lean-Brace Joints. Journal of Beijing University of Technology 2015(accepted)

Liu Xue-chun, Zhang Ai-lin, Huang Huan, et al(2015). Model test of Modularized Prefabricated Steel Frame with Lean-brace Joint. Journal of Beijing University of Technology 2015(accepted)

Qu Zhe, Ye Lieping, Pan Peng(2011). Comparative study on methods of selecting earthquake ground motions for nonlinear time-history analyses of building structures. China Civil Engineering Journal 2011;44(7):10-21.

Wang Wei, Chen Yiyi, Yu Yachao, et al(2012). Floor-by-floor assembled steel braced structures for prefabricated buildings. Building Structure 2012;42(10):48-52.

Zhang Ailin, Liu Xuechun(2013). The new development of industrial assembly high-rise steel structure system in China. Proceedings of Tenth Pacific Structural Steel Conference, Singapore, 8-11 October, 2013:976-981. 